\title{
Observing Havruta Learning from the Perspective of the Learning Sciences
}

Baruch Schwarz

Tn this chapter, Baruch Schwarz applies the lens of the learning sciences to 1 analyze the havruta (paired) learning that is characteristic of ultra-orthodox yeshivot. He begins with a description of the learning that takes place in these settings, providing a glimpse into a context unseen by many Jewish educational researchers. In these yeshivot, havruta learning is marked by intense interpersonal engagement and argumentation, often motivated by what Schwarz calls the learners' sense of the worthiness of the activity. Though aware of the important differences between ultra-orthodox and liberal educational settings, he nonetheless argues that they can inform one another. For example, Schwarz addresses the relevance of the sense of the worthy as a motivational factor even in settings, such as pluralistic schools, where one may imagine that there is less consensus about what is worthy.

The present chapter presents Havruta learning - the traditional dyadic learning of Talmudic texts - in Haredi (i.e., ultra-orthodox) yeshivas from a Learning Sciences perspective. This educational setting is very unusual in comparison with practices of study in other societies: learners practice the collective reading of argumentative texts, initiate critical discussions on their interpretations as the most central educational practice, and, since Talmudic texts are normative within the culture, try to infer from their interpretations how to behave. In addition, Havruta learners enact these practices intensively as they pursue their studies for years from early adolescence to adulthood. Rabbis first control Havruta learning, but along the years, learners become 
autonomous. The thorough engagement of learners and their tenacity contrast with the ways students typically learn in schools.

Through the analysis of several interactions between Havruta learners, as well as interviews of yeshiva students, we identify the motivation that moves Havruta learners in their complex studies for years, as well as some learning mechanisms that characterize the argumentative dialogue as it deploys itself in the conversation. The interviews point at an intensive motivation we call sense of the worthy, a kind of motivation not observed in schools and not accounted for in motivation theories. The mechanisms directly observed are unique, especially in the ways Havruta learners capitalize on the texts as resources in their argumentative dialogue. Ironically, the mechanisms observed, as well as the motivation reported, have important implications for liberal education, and for Jewish education, but not in directions that leaders of the yeshiva would likely endorse.

We will also draw conclusions concerning the relevance of yeshiva learning to the Learning Sciences. The recent developments in the organization of the social setting of classrooms favor teacher-guided and autonomous small-group work. ${ }^{1}$ However, studies that explore the effects of long term small group work practices are badly missing. The yeshiva context is an interesting environment for studying the development of knowledge, argumentative skills, autonomy and identity over the long term, from early adolescence to early adulthood. Such studies may provide insights for educators interested in the intensive fostering of small group learning. Finally, we will briefly reflect on a more integrative perspective of yeshiva learning and the Learning Sciences to consider novel and constructive directions in Jewish education.

\section{Havruta: A Central Practice in Yeshivas}

Havruta, also pronounced Havrussa (from the Aramaic for "friendship"), is a traditional approach to Talmudic study in which a pair of students autonomously learn, discuss, and debate a shared text. While this is not the place for a history of the practice, it is worth noting that Havruta was not very popular in the heyday of the Lithuanian Yeshivas in the nineteenth century,

1 Noreen M. Webb, "The Teacher's Role in Promoting Collaborative Dialogue in the Classroom," British Journal of Educational Psychology 79, no. 1 (2009), 1-28. 
as many elite students preferred learning individually. ${ }^{2}$ However, the transformation of Haredi society into a community of learners in the middle of the twentieth century positioned Havruta as the focal point of yeshiva-based study of the Talmud.

In Haredi yeshivas, dyads learn in the study hall-the Beit Hamidrash or Beis Medrash. The Beit Hamidrash is a special space, with a certain sanctity but also, during study, a dull roar of voices. Depending on the size of the yeshiva, dozens or even hundreds of Havruta dyads can be heard discussing and debating each other's opinions. The head of the yeshiva or other senior rabbis typically sit in the back of the Beit Hamidrash and study alone. Students sometimes consult them, when dyads get stuck on a difficult point or need further clarification, but Havruta learning is primarily an autonomous activity for dyads.

Havruta learning in this setting tends to be loud and animated, as the study partners read the Talmudic text and the commentaries aloud to each other and then analyze, question, debate, and defend their points of view to arrive at a mutual understanding of the text. Given that students typically spend the whole day, or most of the day, learning beside hundreds of other dyads, the term "total institution" coined by Erving Goffman ${ }^{3}$ seems to perfectly fit this setting. At times, groups of advanced dyads gather in a Habura to hear about new interpretations by others, and to present to other learners the conclusions of their dyadic efforts. This auto-organization has social implications: it is in Haburas that bright students are identified through peer evaluation. The Habura provides social validation for the efforts of the dyad, for better or for worse. Daily Havruta learning cannot be understood without taking into account that the interpretations of dyads are regularly evaluated, and these evaluations impinge on the image of the learners in their yeshiva, and more generally, in their society.

In the general structure of a day of study in yeshivas, the only activity that resembles school learning is the Shiur-a kind of lecture led by an instructor. But even the Shiur is different from teacher-led discussions in classrooms: the instructor asks difficult questions of the students, advances arguments, and is asked harsh questions in turn as students vie to refute his

2 Immanuel Etkes and Shlomo Tikochinski, eds. Memoirs of the Lithuanian Yeshiva (Jerusalem: Zalman Shazar Center for Jewish History, 2004).

3 Erving Goffman, Asylums: Essays on the Condition of the Social Situation of Mental Patients and Other Inmates (New York: Anchor Books, 1961). 
arguments. And challenges and refutations are always based on commentators of the Talmud.

In the yeshivas designed for unmarried young men, learners typically study Talmudic texts without accounting for the application of their new understanding to any objective. They embrace a norm within rabbinic literature on the central religious importance of Torah study, rather than learning Torah for extrinsic purposes. Learning Torah is a commandment, and fulfilling the commandments is a central goal demanded from all (religious) Jews. Thus, the motivation of Torah learning should be total obedience as a way to express one's belief in God. At the same time, members of this community tend to see the fulfillment of the commandments as an honor rather than a burden, as reflected in the following Talmudic saying: "One who acts because he is commanded to do so is greater than one who acts without being commanded" (b. Kiddushin 31b).

Another leitmotiv of the rabbinic literature on Torah learning is that, in spite of the apparently coercive nature of this and other practices, they lead to freedom. A Midrashic interpretation of the biblical verse that the word of God "was inscribed on tablets of stone" (Exodus 32:16) plays with the word "inscribed" (harut) to make the point: "Do not read it as inscribed" (harut) but rather 'freedom' (herut)" (Exodus Rabbah 41). Obedience as a way to express one's belief, learning for its own sake, and attaining freedom are three major themes of rabbinic literature on Torah learning.

And yet, even given this cultural context, we may wonder how adolescents or young adults can sit together for ten or even twelve hours per day, six days a week, for years, poring over the tomes of the Talmud. Moreover, the content of the Talmudic text - the fact that the material is often obsolete and often obscure-augments the strangeness of this phenomenon. As we proceed, we will identify what Havruta learners say about their motivation for their daily learning. We were convinced, initially, that since yeshiva students know well the rabbinic literature about the importance of Torah study, they would be inclined to recite by heart what they read and heard about the topic. And indeed, many learners have internalized those messages. However, our interviews uncover a richer picture, which goes beyond the mere recitation of memorized formulae.

But before turning to this data, we would like to note an important characteristic of Talmudic texts that is highly relevant to the question of motivation, namely, their strongly normative character: The discussions among sages in 
the Talmud are very often about how one should behave in religious or civil matters. We might think, therefore, that yeshiva students engage in the study of Talmud in order to improve their behavior, to bring it into conformity with the dictates of the tradition. However, the situation is not so simple.

The Halakha - the collective body of Jewish religious law derived from a number of sources, but especially from the Talmud-is compiled in post-Talmudic codes and responsa literature. Poskim, decisors, of whom there are only a few who are acknowledged in any generation, have done the job of inferring the law from the Talmud on virtually any human activity, and the new and challenging questions that arise-due to new technologies, for example-are considered to be the exclusive domain of those leading poskim. What is left for the yeshiva student to do? To understand how the already-known Jewish law can be inferred from the Talmud.

Such an activity can be a bit dangerous because the learner is exposed to a literature in which legislators often disagree and present the reasons for their decisions. Learners might be inclined to take sides, something that endangers the strict hierarchy in the very conservative world of Haredi Jewry. This kind of activity (which is called "Aliba de-hilkheta") was very rare in Haredi yeshivas for the reasons just mentioned. However, it is now flourishing in many kollels (yeshivas for married men). In these kollels, in-depth learning of Talmudic texts is replaced by the analysis of halakhic texts, rapid review of texts is replaced by reconsideration of Talmudic texts already learned in the past, and the preparation toward tomorrow's in-depth learning is replaced by in-depth learning of relevant Talmudic texts toward the forthcoming analysis of halakhic texts.

\section{Research on Havruta Learning}

In 1986, Courtney Cazden claimed that no research had been done at that time on this important practice, and stressed that research should focus "... on the coincidence of intellectual, emotional, and religious experience and not only on the ensuing (and presumably more intellectual) discussion." ${ }^{4}$ Since then, a research program undertaken by Elie Holzer, Orit Kent, and their colleagues has focused on pedagogies and teacher education programs to introduce

4 Courtney B. Cazden, "Classroom Discourse," in Handbook of Research on Teaching, 3rd ed., ed. Merlin C. Wittrock (New York: Macmillan Publishing Company, 1986), 133. 
students outside the yeshiva to dyadic study of ancient texts. ${ }^{5}$ These interesting programs share in common a focus on interactional components, or what is called a "relational epistemology" 6 combined with a "relational paradigm of teaching and learning." 7 The texts are short, tailored to the context, and are provided with extensive scaffolding, including translation from the original Aramaic and Hebrew. ${ }^{8}$

In some other publications, general ideas about the suitability of Havruta learning to modern pedagogies are articulated. ${ }^{9}$ Sometimes, important details from observations of Havruta learners are stressed. For example, Susan Tedmon ${ }^{10}$ notices the vividness of Havruta learning among middle school youngsters who refer to the exegete Rashi (1040-1106) by saying "Rashi says. .." instead of "Rashi said. . ." and who collaborate in the construction of new interpretations of their own. However, such descriptions are episodic rather than systematic, or aspire to develop models of what Havruta learning ought to be as opposed to what it is. Recently, Holzer and Kent ${ }^{11}$ have clearly articulated this idealized model in the light of advances in modern pedagogies and theories of learning.

Some researchers have initiated systematic analyses of actual Havruta learning in Haredi and orthodox yeshivas. For example, Menahem Blondheim

5 For example, Sharon Feiman-Nemser, "Beit Midrash for Teachers: An Experiment in Teacher Preparation," Journal of Jewish Education 72, no. 3 (2006), 161-81; Elie Holzer, "What Connects 'Good' Teaching, Text Study and Hevruta Learning? A Conceptual Argument," Journal of Jewish Education 72, no. 3 (2006), 183-204; Orit Kent, "Interactive Text Study: A Case of Hevruta Learning," Journal of Jewish Education 72, no. 3 (2006), 20532; Orit Kent, "A Theory of Havruta Learning," Journal of Jewish Education 76, no. 3 (2010), 215-45; Miriam Raider-Roth and Elie Holzer, "Learning to be Present: How Hevruta Learning Can Activate Teachers' Relationships to Self, Other and Text," Journal of Jewish Education 75, no. 3 (2009), 216-39.

6 Raider-Roth and Holzer, "Learning to be Present," 219-20.

7 Ibid., 220.

8 See also, Moshe Abelesz, "Encouraging Successful Gemara Learning for Boys of Religious Zionist and Modern Orthodox Backgrounds in Israeli State Religious High Schools," ATID Journal (2000), http://www.atid.org/journal/journal00/default1.asp; Moshe Genuth et al., "Hora'at haTalmud vehahakhanah labagrut: Sihot im Misrad haHinnukh, morim, venituah homerei ezer," ATID Journal (2001), http://www.atid.org/journal/journal01/default1.asp.

9 Steven M. Brown and Mitchel Malkus, "Hevruta as a Form of Cooperative Learning," Journal of Jewish Education, 73, no. 3 (2007), 209-26.

10 Susan Tedmon, "Collaborative Acts of Literacy in a Traditional Jewish Community" (PhD diss., University of Pennsylvania, 1991).

11 Elie Holzer and Orit Kent, A Philosophy of Havruta: Understanding and Teaching the Art of Text Study in Pairs (Boston: Academic Studies Press, 2014). 
and Shoshana Blum-Kulka ${ }^{12}$ have provided fine-grained descriptions of Havruta discussions among young learners from a National-Religious yeshiva, that demonstrate how learners successfully handle disagreements in interaction. These descriptions are instructive, but they focus on novice students within the mainstream education system who have not yet mastered the techniques of Havruta learning. Likewise, Segal ${ }^{13}$ describes Havruta interactions in institutional settings in which learners are novices, focusing on relations between the lessons of the Rabbi and Havruta sessions rather than on the learning processes involved in Havruta settings. My own research has focused specifically on experienced Havruta learners in Haredi institutions: the Mir Yeshiva ${ }^{14}$ and in a Slobodka kollel. ${ }^{15}$

These studies have uncovered the following interesting phenomena:

- The high argumentativeness of the learners, including the deployment of impressive argumentative practices: the reconstitution of complex arguments agreed upon in a previous session (to initiate a new discussion); critical evaluation of sources; critical discussions governed by high-level dialectic rules; ${ }^{16}$

- The relatively aggressive style oflearners when handling disagreements; ${ }^{17}$

12 Menahem Blondheim and Shoshana Blum-Kulka, "Literacy, Orality, Television: Mediation and Authenticity in Jewish Conversational Arguing, 1-2000 C.E.," The Communication Review 4, no. 4 (2001), 511-40; Shoshana Blum-Kulka et al., "Traditions of Dispute: From Negotiations of Talmudic Texts to the Arena of Political Discourse in the Media," Journal of Pragmatics 34, no. 10-11 (2002), 1569-94.

13 Aliza Segal, "Schooling a Minority: The Case of Havruta Paired Learning," Diaspora, Indigenous, and Minority Education: Studies of Migration, Integration, Equity, and Cultural Survival 7, no. 3 (2013), 149-63.

14 Baruch B. Schwarz, "'Hevruta' Learning in Lithuanian Yeshivas: Recurrent Learning of Talmudic Issues," in Education and Religion: Authority and Autonomy, ed. Immanuel Etkes et al. (Jerusalem: Magnes Publishing House, 2011), 279-308; Baruch B. Schwarz, "Discussing Argumentative Texts as a Traditional Jewish Learning Practice," in Socializing Intelligence Through Academic Talk and Dialogue, ed. Lauren B. Resnick et al. (Washington, DC: American Educational Research Association, 2015), 153-62.

15 Baruch B. Schwarz, "Authoritative or Authoritarian Voices in Traditional Learning in Jewish Institutions," in Activities of Thinking in Social Spaces, ed. Tania Zittoun and Antonio Iannaccone (Hauppauge, NY: Nova Science Publishers, 2014), 129-46.

16 Schwarz, "Hevruta' Learning in Lithuanian Yeshivas," 279-308; Schwarz, "Discussing Argumentative Texts," 153-62.

17 Blondheim and Blum-Kulka, "Literacy, Orality, Television," 511-40. Like Blondheim and BlumKulka, we observed that very often disagreements occurred in Havruta interactions by asserting that the claim contested is not relevant to the issue at hand. A linguistic study has shown that disagreements on arguments in conversations are of four types: irrelevancy claims, challenges, 
- The high level of collaboration between peers: although the Talmudic text is often adversarial, and despite the aggressiveness mentioned above, students tend to adopt a collaborative atmosphere rather than a disputational style in their interactions. ${ }^{18}$

- A high level of autonomy and independence: learners indicate that they feel a great deal of freedom in the interpretative realm, and try not to approach helpers (instructors, more able students, or even written material that eases the comprehension of texts) in their Havruta learning when they encounter difficulties; ${ }^{19}$

- Audacious reference to authority: learners express the freedom to uncover interpretations that differ from the interpretations of even senior rabbis in their yeshivas, and point out that the rabbis are human like them and may make mistakes (although dissidence does not impinge on rules of behavior that are decided by the rabbis only). Also, among experienced learners, there is a clear autonomous stand toward the authority of rabbis, or even from recent texts written by contemporary religious leaders. ${ }^{20}$ Some of the moves of the interactions even show an unsubordinated approach as for interpretation of texts. ${ }^{21}$

The above insights are glimpses of a world of study whose nature is still not very well understood. With my research group, I have begun a systematic analysis of the learning in Havruta as it deploys itself in argumentative dialogue. Most of the insights we reach relate to recurrent patterns of interactions between learners. For example, the collaborative character of Havruta learning is visible in a dialectical pattern in which one learner brings forward an argument (a reasoned claim), his peer asks for clarifications, and the first

contradictions and counterclaims. See Peter Muntigl and William Turnbull, "Conversational Structure and Facework in Arguing," Journal of Pragmatics 29, no. 3 (1998), 225-56. In countries such as the United States, irrelevancy claims are considered very aggressive in comparison with counterclaims, contradictions or even challenges. Blondheim and Blum-Kulka analyzed conversations among Jews to conclude that conversational arguing in Jewish culture is more antagonistic than in other cultures, and suggest that this difference might be imputed to perennial dialectical practices of Torah study culturally rooted even among secular Jews.

18 Reuven Ben-Haim et al., "Making the Written Text Oral by Collaborating in Argumentation: Towards Detecting Chavruta Processes Among Ultra-Orthodox Learners," in Studies in Jewish Education, ed. Jonathan Cohen. (Jerusalem: The Melton Center for Jewish Education, (in press)).

19 Schwarz, "Hevruta' Learning in Lithuanian Yeshivas," 279-308.

20 Schwarz, "Authoritative or Authoritarian Voices," 129-46.

21 Schwarz, "Hevruta' Learning in Lithuanian Yeshivas," 279-308. 
learner expands on his argument. Another pattern consists in the bringing of an argument and an expansion by the peer. The high argumentativeness was visible in a ubiquitous dialectical pattern consisting on an argument, a counter-argument or a challenge (rather than a request for clarification), and a refutation. My research group is currently collecting data to document other patterns that point at processes that characterize Havruta learning in a distinctive way.

The overwhelming presence of argumentation in Havruta interactions is particularly impressive in the light of research that shows that argumentation is rare in learning contexts because learners have difficulties maintaining their motivation to argue. ${ }^{22}$ Moreover, the autonomy and independence of students in Havruta settings deepens the question about what motivates learners in yeshivas, to which we now turn.

\section{Motivation for Learning in Yeshivas}

Not all yeshiva students are equally motivated, of course. But among those students who are identified (by their teachers and fellow students) as being highly motivated, who demonstrate that motivation even in the havruta setting characterized by autonomy and argumentation, what is the nature of that motivation? In interviews of Haredi men and boys living in Israel conducted by Mordecai Nisan and Yishai Shalif ${ }^{23}$ and by my research group ${ }^{24}$, these students were asked questions such as these: Why are you studying Torah? What does this study give you? What is missing for young men who do not study Torah? Is Torah study challenging and, if so, in what way? Are there times when you are not studying Torah? How do you feel then, and why? Is the problem of "what other people think" an important factor in your wish to study Torah? Are there times when studying is difficult? How do you convince yourself to keep on studying?

The interviewees tended to explain their motivation to study Torah first and foremost in terms of the religious commandment, their sense of obligation, and their notion of what is worthy and what is good. They considered

22 Baruch B. Schwarz and Amnon Glassner, "The Blind and the Paralytic: Fostering Argumentation in Social and Scientific Domains, in Arguing to Learn: Confronting Cognitions in Computer-Supported Collaborative Learning Environments, ed. Jerry Andriessan et al. (Dordrecht, Netherlands: Kluwer Academic Publishers, 2003), 227-60.

23 Mordecai Nisan and Yishai Shalif, "The Sense of the Worthy as a Motivation for Studying: The Case of the Yeshiva," Interchange 37, no. 4 (2006), 363-94.

24 Ben-Haim et al., "Making the Written Text Oral," in Cohen, Studies in Jewish Education. 
this explanation to be totally obvious, and offered various formulations of the basic assertion, "We have to study the Torah because God said so, and there is a commandment to study the Torah."

Perceiving Torah study as a worthy pursuit motivates the students directly and immediately in the study situation, and at the same time has the status of a meta-conception that determines the value and legitimacy of activities at the yeshiva and the feelings associated with them. This sense of the worthy is manifested in its influence on other motivational factors. The interviewees are aware of these other factors and mention them: considerations of utility and long-term interests (such as obtaining a good teaching position at the yeshiva or being given the opportunity to marry a worthy woman), social pressure and assessment, intellectual challenge and interest, and what sounds to the psychologist like a need for self-actualization. In other words, these other factors are based on the assessment of yeshiva studies as worthy and good. Without such an assessment, all the other considerations lose their power.

What is the basis of the sense that Torah study is a worthy pursuit? Most of the men and boys never even asked themselves this question. The life style of Torah study has been a basic fact of their lives for as long as they can remember. As one of the Yeshiva students declared in his interview: "Why do I study the Torah? Because 'this is our life' [a quotation from the daily prayer service .... You should ask the fish why they want to be in the water-because that is how they live." Nevertheless, when they are asked to explain the value of Torah study, yeshiva students offered well-developed justifications. The answers can be categorized into three views: (a) it is a commandment, (b) it is necessary for self-improvement and growth, and (c) it is a fulfillment of the purpose of life.

In the first view, obedience to a commandment without any other reason for acting is the greatest manifestation of the worship of God, or the worthy life. Torah study is done purely for its own sake, as opposed to doing it for the sake of some extrinsic reward. In the second view, the value of Torah study stems from its contribution to human improvement. It is seen as the natural way to promote human development and perfection - not as an instrument that can be replaced by some other, but as an activity that embodies human development and flourishing. Development is not limited to intellectual achievement, such as understanding the Torah or sharpening the mind, but expands to include the acquisition of virtues and proper ways of behaving toward others. In the third view, Torah study is seen as the purpose of human life. The goal is to know the true and the good, and this knowledge is achieved through study 
of the Torah. Torah study in and of itself constitutes the individual's humanity, the realization of his ultimate purpose and the meaning of life. This view of the motivation for Torah study goes beyond the fulfillment of the commandment and attempts to reach its meaning.

The view of Torah study as worthy is considered obvious in the interviews. In general in human activities, obviousness obstructs awareness. In our interviews, it was the contrary, as learners were fully aware of the worthiness of Torah study. The answer to this oddity may be found in the prevalent view at the yeshiva that Torah study must always be accompanied by awareness that it is a divine commandment and consciousness of its worth. Many of the interviewees mentioned the distinction between "studying Torah for its own sake," and "studying Torah not for its own sake," for some extrinsic purpose, such as attaining social esteem. Many of the interviewees quoted the aforementioned Talmudic saying, "Doing it not for its own sake leads to doing it for its own sake." This saying defends studying Torah not for its own sake yet at the same time expresses reservations about this practice. The "sense of the worthy" is thus nourished by the normative expectation of such awareness - an explicit demand that Torah study be based on the sense of the worthy rather than extrinsic reasons.

Moreover, in the interviews, what we are calling the "sense of the worthy" comfortably co-exists with a sense of autonomy: students see the commandment of studying Torah not as lessening their freedom but as enhancing it. The contradiction between the idea that the Torah was forced on the Jewish people (e.g., in b. Shabbat 88a) and the status of free will in the fulfillment of the commandments is a familiar dilemma among yeshiva students. The commandments do not limit human freedom but make it possible and even enhance it, as they free the individual from coercions that he may not even be aware of and open up new opportunities. Haredi Jews feel that, within the "coerced" setting of the commandment to study the Torah, the yeshiva not only allows for, but even encourages, a space for personal expression. Structurally, students have autonomy to choose their own Havruta partners, and as noted above, the Habura - the gathering of different dyads every two weeks to report on progress in learning - is student-organized and led. When a student presents an interpretation in a Habura that is recognized as novel and particularly worthy, it is disseminated among other Haburas.

There are also other positive motivations for learning in yeshiva. For example, the Yiddish word geschmack - meaning a sort of superior flavor-is used to describe the pure pleasure or satisfaction gained from the act of Torah 
study itself. Some of the types of satisfaction may appeal to Western psychological theories of motivation:

- "The material itself exerts a pull on you" (curiosity and interest);

- "You discover strengths within yourself, you are renewed and also reveal a new person" (self-discovery and identity creation);

- "I can express myself. ... I can realize myself" (self-actualization).

- Other types of satisfaction are anchored in religious views:

- "You feel closeness to the thing you are studying.... You feel close to the one who gave us the Torah";

- "Someone who studies Torah feels that he is holding the world together... I am involved in bringing rain to the world, I am involved in bringing peace to the land."

My own working hypothesis is that the feeling of geschmack partly relates to the dialectical character of Havruta argumentation, involving tension (disagreement, challenge) and relaxation (resolution, explanation). Researchers in argumentation have recognized this alternation as being accompanied by pleasant emotional states. $^{25}$

\section{What can Liberal Education Learn from Yeshiva Learning?}

The unusual enthusiasm and the tenacity of Havruta learners in yeshiva may easily generate envy among promotors of liberal education, including liberal Jewish education. Is yeshiva learning relevant to liberal education? What can liberal education learn from yeshivas? To be sure, from the perspective of liberal educators, the yeshiva embodies major defects such as the indoctrination of students to a narrow, closed worldview. Also, liberal educators may be repelled by the very notion of normative motivation in schools. We will return to these major issues later on. However, we can also identify other aspects of Havruta learning that are highly relevant to modern pedagogies.

Most fundamentally, of course, Havruta learning is based on a collaborative setting in dyads. Progressive pedagogies are committed to reducing both teacher-led discussions and individual work, in favor of small-group work. ${ }^{26}$

25 Jerry Andriessen et al., "Socio-Cognitive Tension in Collaborative Working Relations," in Learning Across Sites: New Tools, Infrastructures and Practices, ed. Sten R. Ludvigsen et al. (London: Routledge, 2011), 222-42.

26 For example, Webb, “The Teacher's Role," 1-28. 
Schools often implement collaboration among students — but far less comprehensively than in yeshivas.

Beyond this dyadic structure, the learning task in the yeshiva is organized around texts that present different and often conflicting viewpoints, whereas school learning has traditionally been organized around canonical, monological texts. This may be changing. For example, in history classes, activities may be designed around the comparison of texts representing different narratives. ${ }^{27}$ In science education, socio-scientific dilemmas are presented through texts that convey divergences of opinion concerning science-based solutions to socially relevant issues. ${ }^{28}$ The pedagogy to be adopted, to lead students into consideration of conflicting views, has been recognized as argumentative. However, this pedagogy is still embryonic, and the preliminary free questioning which is so common in yeshiva learning is an important practice to be considered.

Relatedly, the texts studied in yeshiva often show how different religious authorities have reached their conclusions, including their doubts, dead ends and rebutted arguments, and the challenges they faced when confronting the views of antagonists. Some researchers have recently adopted a similar approach in science education: Students are presented Adapted Primary Literature (APL) texts that report not only on results but also the process through which these results were discovered, including doubts or hypotheses rejected after being tested. ${ }^{29}$ But the use of APL texts in science classrooms has been tested with high-level students only, and for a short period of time. Can such a practice be democratized?

Let us consider, next, the question of motivation. Of course, I have not focused on disengaged students, or on students who have difficulties in following the daily pace imposed by the yeshiva. Nevertheless, the interviews performed by Nisan and Shalif ${ }^{30}$ confirmed my own overall impression, which was the

27 For example, Janet van Drie and Carla van Boxtel, "Historical Reasoning: Towards a Framework for Analyzing Students' Reasoning about the Past," Educational Psychology Review 20, no. 2 (2008), 87-110; Sam Wineburg, "On the Reading of Historical Texts: Notes on the Breach Between School and Academy," American Educational Research Journal 28, no. 3 (1991), 495-519.

28 For example, Troy D. Sadler and Dana L. Zeidler, “The Significance of Content Knowledge for Informal Reasoning Regarding Socioscientific Issues: Applying Genetics Knowledge to Genetic Engineering Issues," Science Education 89, no. 1 (2005), 71-93.

29 For example, Ayelet Baram-Tsabari and Anat Yarden, "Text Genre as a Factor in the Formation of Scientific Literacy," Journal of Research in Science Teaching 42, no. 4 (2005), 403-28.

30 Nisan and Shalif, "The Sense of the Worthy," 363-94. 
overwhelming motivation generated by a sense of the worthy. Yeshiva students are products of an authoritative society. Toddlers in that society learn unequivocally what is good and bad; they recite by heart prayers and psalms, and are taught to fulfill commandments as ways to obey their Creator. Yeshivas are total institutions that isolate students from outside influences. They function to strengthen cohesion in communities: learning well in the Yeshiva ensures social recognition, and alliance with good families. However, within this context, during the arduous Havruta learning that lasts ten or twelve hours a day, the motivation expressed as a sense of worthy remains steady, and authoritative voices are not perceivable. This is a remarkable achievement from which liberal education can learn.

But what to learn? Pluralism encourages openness to many views and cultures, and recognizes their legitimacy, apparently obviating any possibility of adopting an ethical orientation or all-embracing educational approach based on uncontested goals and consistent views among all participants. I want to claim that this is incorrect: a sense of the worthy can and should serve as a motivational factor in liberal, pluralistic schools. For example, Galston ${ }^{31}$ argues that, beyond all the controversies about what is good, there is still a considerable set of behaviors that are widely agreed to be worthy and appropriate. Also, even though liberal thinkers hesitate to impose their ideas on schoolchildren, there is still broad agreement that non-instrumental subjects should be included in the school curriculum. Moreover, even if one denies that some texts are sacred, there are nevertheless texts that are valued as prime creative works in a particular culture. Finally, despite reservations about character education in schools, I would argue that education should aim at developing good traits without being self-righteous or indoctrinating. Pluralism and its apparent ramifications, such as recognizing the legitimacy of other people's values and undermining the authority of the educator, do not eliminate the entire realm of the good and the worthy; rather, they too become values. Liberal schools may never look like yeshivas, but they can still aspire to cultivate a sense of the worthy in their own ways.

The fact that the yeshiva embodies a number of aspects that progressive educators find problematic (indoctrination, imposition of a normative motivation, social conservatism) should not prevent them from drawing lessons from it, including from the basic idea of normative motivation-the sense of the worthy. The yeshiva students observed in their studies and interviewed tend

31 William Galston, "Civic Education in the Liberal State," in Philosophers on Education, ed. A. Oxenberg Rorty (London: Routledge, 1998), 470-80. 
not to feel any sense of coercion or impairment of their autonomy. They feel good about their studies, which are not focused on measurable aspects of the material to be learned, and their intrinsic motivation is enhanced by their sense of the worthy. The normative motivation in the yeshiva does indeed act in the direction of cultural conservatism, but there is no reason to believe that this direction - which stems from the yeshiva's educational purpose-is a necessary aspect of all forms of normative motivation. The sense of the worthy in one's studies can be realized in different ways, and there can be negotiations and compromises about the degree to which it should be taken into account. It is thus worth investigating whether there can be normative motivation that leaves room for negotiation between the teachers and the students about the sense of the worthy itself, the justifications for it, and the ways of realizing it.

What should be the messages of liberal schools? The first step is to be aware of the fact that liberal educators have a message. A second step would be that they should strive for a greater degree of clarity and consistency in the conceptions of the worthy that constitute, or that are embodied by, school curricula and extracurricular activities. Providing a clear message-to students, to parents, and to teachers - about the purposes of school studies and the reasons for these purposes is a must, especially those that are not instrumental. It is also important to institute activities connected with the goals, to coordinate lessons and activities with regard to their ethical significance, and to explain the reasons for these purposes and the studies associated with them.

But what are the master ideas of liberal education in the twenty-first century? What are the normative commitments around which education can be organized, in the way that yeshiva education is organized around the centrality of Torah study? Beyond the idea of pluralism, which is totally absent from Haredi yeshivas, our observation of Havruta learning makes salient three other, central characteristics of progressive pedagogies. First, liberal educators are committed to dialogism. Operationally, this means the obligation to express one's own view to the other, to respect the other and account for the other's view, and to construct one's account on the basis of previous contributions. The second characteristic of Havruta learning that is relevant here is its collaborative character. Liberal educators have emphasized the importance of collaboration, not only as a conduit for better learning but as a goal for its own sake. However, collaboration brings a consensual view of dialogism which constrains liberal education $^{32}$, so a dialectic-critical approach to resolve conflicts is also necessary.

32 Robin J. Alexander, Towards Dialogic Teaching: Rethinking Classroom Talk (York: Dialogos, 2005). 
In my own work, I have developed pedagogies involving different forms of argumentative talk to enact these four commitments - pluralism, dialogism, collaboration, and dialecticity. ${ }^{33}$ Notably, these four ideas have been articulated differently by Sarah Michaels, Catherine O'Connor, and Lauren Resnick as Accountable Talk. ${ }^{34}$ For them, Accountable Talk means (1) accountability to the learning community, in which participants listen to and build their contributions in response to those of others, (2) accountability to accepted standards of reasoning, that is, talk that emphasizes logical connections and the drawing of reasonable conclusions; and (3) accountability to knowledge, that is, talk that is based explicitly on facts, written texts, or other public information. Accountable Talk has been enacted in hundreds of schools in the United States. One of the reasons of this success, we propose, is the clarity and the assertiveness of its proponents. Like our colleagues in yeshivas, they communicate their own sense of the worthy.

Of course, there is no place in a liberal school for a strict ethical orientation in which all lessons and activities are subordinated to a worldview directed at the worthy. Nevertheless, liberal education will benefit from a clear articulation of learning goals that incorporate pluralism, dialogism, collaboration, and dialecticity as worthy goals per se, beyond the acquisition of knowledge.

33 Baruch B. Schwarz, "Argumentation and Learning," in Argumentation and Education: Theoretical Foundations and Practices, ed. Nathalie Muller Mirza and Anne-Nelly PerretClermont (New York: Springer, 2009), 91-126; Baruch B. Schwarz and Christa S. C. Asterhan, "Argumentation and Reasoning," in International Handbook of Psychology in Education, ed. Karen Littleton et al.(Bingley, UK: Emerald Group Publishing, 2010), 137-76.

34 Sarah Michaels et al., "Deliberative Discourse Idealized and Realized: Accountable Talk in the Classroom and in Civic Life," Studies in Philosophy and Education 27, no. 4 (2008), 283-97. 


\section{Bibliography}

Abelesz, Moshe. "Encouraging Successful Gemara Learning for Boys of Religious Zionist and Modern Orthodox Backgrounds in Israeli State Religious High Schools.” ATID Journal, 2000. http://www.atid.org/journal/journal00/default1.asp.

Alexander, Robin. J. Towards Dialogic Teaching: Rethinking Classroom Talk. York: Dialogos, 2005. Andriessen, Jerry, Michael Baker, and Chiel van der Puil. "Socio-Cognitive Tension in Collaborative Working Relations." In Learning Across Sites: New Tools, Infrastructures and Practices. Edited by Sten R. Ludvigsen, Andreas Lund, Ingvill Rasmussen, and Roger Säljö, 222-42. London: Routledge, 2011.

Baram-Tsabari, Ayelet, and Anat Yarden. "Text Genre as a Factor in the Formation of Scientific Literacy." Journal of Research in Science Teaching 42, no. 4 (2005), 403-28.

Ben-Haim, Reuven, Zvi Bekerman and Baruch B. Schwarz. "Making the Written Text Oral by Collaborating in Argumentation: Towards Detecting Chavruta Processes Among UltraOrthodox Learners. In Studies in Jewish Education. Edited by Jonathan Cohen. The Melton Center for Jewish Education. Jerusalem, in press.

Blondheim, Menahem, and Shoshana Blum-Kulka. "Literacy, Orality, Television: Mediation and Authenticity in Jewish Conversational Arguing, 1-2000 C.E." The Communication Review 4, no. 4 (2001), 511-40.

Blum-Kulka, Shoshana, Menahem Blondheim, and Gonen Hacohen. "Traditions of Dispute: From Negotiations of Talmudic Texts to the Arena of Political Discourse in the Media." Journal of Pragmatics 34, no. 10-11 (2002), 1569-94.

Brown, Steven M., and Mitchel Malkus. "Hevruta as a Form of Cooperative Learning." Journal of Jewish Education, 73, no. 3 (2007), 209-26.

Cazden, Courtney B. "Classroom Discourse." In Handbook of Research on Teaching, 3rd ed. Edited by Merlin C. Wittrock, 432-63. New York: Macmillan Publishing Company, 1986.

Etkes, Immanuel, and Shlomo Tikochinski, eds. Memoirs of the Lithuanian Yeshiva. Jerusalem: Zalman Shazar Center for Jewish History, 2004.

Etkes, Immanuel, Michael Heyd, Tamar Elor, and Baruch Schwarz. Education and Religion: Authority and Autonomy. Jerusalem: Magness Publishing House, 2011.

Feiman-Nemser, Sharon. "Beit Midrash for Teachers: An Experiment in Teacher Preparation." Journal of Jewish Education 72, no. 3 (2006), 161-81. 
Galston, William. "Civic education in the liberal state." In Philosophers on Education. Edited by A. Oxenberg Rorty, 470-80. London: Routledge, 1998.

Genuth, Moshe, Avital Hockstein, Adina Luber, and Yael Wieselberg. "Hora'at haTalmud vehahakhanah labagrut: Sihot im Misrad haHinnukh, morim, venituah homerei ezer." ATID Journal, 2001. http://www.atid.org/journal/journal01/default1.asp.

Goffman, Erving. Asylums: Essays on the Condition of the Social Situation of Mental Patients and Other Inmates. New York: Anchor Books, 1961.

Holzer, Elie, and Orit Kent. A Philosophy of Havruta: Understanding and Teaching the Art of Text Study in Pairs. Boston: Academic Studies Press, 2014.

Holzer, Elie. "What Connects 'Good' Teaching, Text Study and Hevruta Learning? A Conceptual Argument." Journal of Jewish Education 72, no. 3 (2006), 183-204.

Kent, Orit. "A Theory of Havruta Learning." Journal of Jewish Education 76, no. 3 (2010), 215-45. . "Interactive Text Study: A Case of Hevruta Learning." Journal of Jewish Education 72, no. 3 (2006), 205-32.

Mercer, Neil. "Words and Minds: How We Use Language to Think Together." London: Routledge, 2000.

Michaels, Sarah, Catherine O'Connor, and Lauren B. Resnick. "Deliberative Discourse Idealized and Realized: Accountable Talk in the Classroom and in Civic Life." Studies in Philosophy and Education 27, no. 4 (2008), 283-97.

Muntigl, Peter, and William Turnbull. "Conversational Structure and Facework in Arguing." Journal of Pragmatics 29, no. 3 (1998), 225-56.

Nisan, Mordecai, and Yishai Shalif. "The Sense of the Worthy as a Motivation for Studying: The Case of the Yeshiva." Interchange 37, no. 4 (2006), 363-94.

Raider-Roth, Miriam, and Elie Holzer. "Learning to be Present: How Hevruta Learning Can Activate Teachers' Relationships to Self, Other and Text." Journal of Jewish Education 75, no. 3 (2009), 216-39.

Sadler, Troy D., and Dana L. Zeidler. "The Significance of Content Knowledge for Informal Reasoning Regarding Socioscientific Issues: Applying Genetics Knowledge to Genetic Engineering Issues." Science Education 89, no. 1 (2005), 71-93.

Schwarz, Baruch B. "Argumentation and Learning." In Argumentation and Education: Theoretical Foundations and Practices. Edited by Nathalie Muller Mirza and Anne-Nelly Perret-Clermont, 91-126. New York: Springer, 2009.

"Authoritative or Authoritarian Voices in Traditional Learning in Jewish Institutions." In Activities of Thinking in Social Spaces. Edited by Tania Zittoun and Antonio Iannaccone, 129-46. Nova Science Publishers, 2014.

. "Collective Reading of Multiple Texts in Argumentative Activities." International Journal of Educational Research 39, no. 1-2 (2003), 133-51.

"Discussing Argumentative Texts as a Traditional Jewish Learning Practice." In Socializing Intelligence Through Academic Talk and Dialogue. Edited by Lauren B. Resnick, Christa S. C. Asterhan, and Sherice N. Clarke, 153-62. Washington, DC: American Educational Research Association, 2015. 
. "Hevruta' Learning in Lithuanian Yeshivas: Recurrent Learning of Talmudic Issues.” In Education and Religion: Authority and Autonomy. Edited by Immanuel Etkes, Michael Heyd, Tamar Elor, and Baruch Schwarz, 279-308. Jerusalem: Magness Publishing House, 2011.

Schwarz, Baruch B. and Christa S. C. Asterhan. "Argumentation and Reasoning." In International Handbook of Psychology in Education. Edited by Karen Littleton, Clare Wood, and Judith Kleine Staarman, 137-76. Bingley, UK: Emerald Group Publishing, 2010.

Schwarz, Baruch B., and Amnon Glassner. "The Blind and the Paralytic: Fostering Argumentation in Social and Scientific Domains. In Arguing to Learn: Confronting Cognitions in ComputerSupported Collaborative Learning Environments. Edited by Jerry Andriessen, Michael Baker, and Daniel Suthers, 227-60. Dordrecht, Netherlands: Kluwer Academic Publishers, 2003.

Segal, Aliza. "Schooling a Minority: The Case of Havruta Paired Learning." Diaspora, Indigenous, and Minority Education: Studies of Migration, Integration, Equity, and Cultural Survival, 7, no. 3 (2013), 149-63.

Tedmon, Susan. "Collaborative Acts of Literacy in a Traditional Jewish Community." PhD diss., University of Pennsylvania, 1991.

van Drie, Janet, and Carla van Boxtel. "Historical Reasoning: Towards a Framework for Analyzing Students' Reasoning about the Past." Educational Psychology Review 20, no. 2 (2008), 87-110.

Walton, Douglas. Appeal to Expert Opinion: Argumentation from Authority. University Park, PA: Penn State Press, 1992.

Webb, Noreen M. “The Teacher's Role in Promoting Collaborative Dialogue in the Classroom.” British Journal of Educational Psychology 79, no. 1 (2009), 1-28.

Wineburg, Sam S. "On the Reading of Historical Texts: Notes on the Breach Between School and Academy.” American Educational Research Journal 28, no. 3 (1991), 495-519. 